\title{
Popularization by Argentine researchers: the activities and motivations of CONICET scientists
}

\author{
Pablo Kreimer, Luciano Levin and Pablo Jensen
}

This paper presents the findings of a survey on popularization activities by 1700 scientists in Argentina. The tool used for this research was a questionnaire containing 21 questions on discipline, age, status in hierarchy, intensity of popularization activity, motives, difficulties and opinions on public issues and science policy. Our analysis of the data shows that patterns of public popularization in Argentina do not substantially differ from those found in two advanced countries, namely France and the United Kingdom. This situation contrasts with the strong differences found in research practices in "central" and "peripheral" countries.

Keywords: popularization of science, public understanding of science, science communication, scientists' opinions, social responsibility of scientists

\section{Introduction}

The overall objective of the study is to characterize the popularization activities of Argentine researchers and to compare them to those observed in advanced countries like France or the United Kingdom (Jensen, 2011; Royal Society, 2006). We investigate whether popularization practices in a "peripheral" country (Kreimer, 1998) differ in any way from practices in "central" countries or if the practices are aligned with the international patterns of the so-called "Realm of Science" (Polanyi, 1964). There is a wide array of literature about the differences between scientific activities carried out in "central" and "peripheral" countries (Gaillard et al., 1996; Kreimer, 1998; Kreimer and Zabala, 2007; Salomon et al., 1994; Schwartzman, 1991; Vessuri, 1983). These studies point out that the ways and practices of conducting research in developing countries have particular features and have been developed in a powerful tension between the "local" conditions and the imperatives of "universalizing" science. They have analyzed the role of national institutions, the links between local and international scientific communities, the emergence of public policies oriented to regulate and/or stimulate research activities, the availability and the use of technical devices inside the labs, and the relationships between scientific research and social/public needs. Overall, these texts have shown that research in such a context presents several particular features. For instance, the establishment of research agendas is strongly influenced by the relationships that "peripheral" groups undertake with their "central" colleagues located in the most prestigious labs and institutions (Kreimer, 1998). Furthermore, cognitive innovation is unlikely to be achieved in 
developing countries, where a large part of research could be classified as "hypernormal" science (Lemaine, 1980).

However, until now, no study has been carried out in Argentina on dissemination activities as a particular component of scientific practice. If we consider dissemination activities as one of the components of the complex set of "science-society" relationships, we have to take into account that in developing countries, there has been traditionally a high degree of autonomy and as a consequence, weak links between scientists with other social actors, particularly with firms and the productive sector in general. Thus, it was of special interest to investigate if scientists' behaviour regarding public popularization follows the same patterns that can be observed in "central" countries, or if it presents particular features. In particular, we want to study how scientists perceive the role of public engagement, as studies carried out in European countries (Boy, 2007; Royal Society, 2006) have shown that their dominant answer is "to explain and promote public understanding of science," a typical feature of the "diffusion" and "deficit" models (Weigold, 2001) of popularization.

The paper is organized as follows. Section 2 specifies the methodology used. Section 3 sets out and discusses the main findings about popularization activities. We describe the general activities of those who do and do not carry out popularization practices and we discuss structural or context-dependent variables that influence a certain "propensity for popularization," such as career position, belonging to a particular disciplinary field, age, gender, or geographical location. We also investigate the factors that - from the perspective of the researchers themselves - act as stimuli or obstacles to popularization activities and whether such assessments depend on any of the variables mentioned above. It is crucial to take into account these findings when designing instruments aimed at promoting science-society relations, implicit in scientific popularization activities.

Finally, we analyse the researchers' perceptions of the role of scientific popularization and the difficulties they encounter when performing this type of activity. Section 4 describes researchers' opinions about a series of issues such as the social role of scientific research and the role of the state to intervene and target research towards social problems as opposed to a laissez-faire strategy. We analyzed their answers according to several variables and characterized them in relation to their popularization activities.

\section{Methodology}

We studied the researchers of CONICET (National Scientific and Technical Research Council) to obtain a controllable sample representative of Argentina's researchers as a whole. CONICET scientists represent around $20 \%$ of the total, and are the most active, prestigious and productive researchers in Argentina. The permanent positions within CONICET are, in order of decreasing hierarchical position: Superior (Senior), Principal, Independiente (Independent), Adjunto (Adjunct) and Asistente (Assistant). Researchers have the status of civil servants, and can work in CONICET's own institutes or in university research centres. Around $60 \%$ of CONICET researchers teach in universities, with a "double status" (professor and researcher). CONICET scientists are classified in the following research areas and disciplines:

- Agrarian Sciences: agrarian sciences, engineering, material sciences, architecture and biotechnology.

- Biological Sciences: medical sciences, biochemistry and veterinary. 
- Exact and Natural Sciences: earth, water and atmosphere sciences, mathematics and computer sciences, physics, astronomy and chemistry.

- Social and Human Sciences: law, political sciences, international affairs, philosophy, education, psychology, history, anthropology, geography, economics, management, philology, linguistics, public administration, demography and sociology, and literature.

- Various or multidisciplinary fields not included in the above categories.

The survey contained 21 questions. It was distributed to all 5162 CONICET researchers in the last week of November 2007 by e-mail, with a link to a dedicated Web page. The answers were collated after one month with a response rate totalling $23.2 \%$ for the questionnaires responded in full.

We compare the respondents to the population surveyed (a figure is available online at http://pus.sagepub.com/content/20/1/37/suppl/DC1). Statistically significant deviations exist for discipline $\left(\chi^{2}=42.1,5\right.$ degrees of freedom, biologists being under-represented), age and position $\left(\chi^{2}=214,6\right.$ degrees of freedom and $\chi^{2}=22.3,5$ degrees of freedom respectively, young scientists being over-represented). The sample is representative for gender $\left(\chi^{2}=1.23, p\right.$-value $\left.=0.26\right)$. The main point is that the response rate does not seem to be systematically biased in favour of scientists active in public engagement as this would lead to an over-representation of the active categories (shown below), i.e. men and higher hierarchical positions. The over-representation of young scientists can be attributed to their willingness to respond to institutional requests, which is arguably uncorrelated with popularization practices. Therefore, the figures drawn from our study can be trusted as representative of the whole CONICET. As an example, calculating the activity percentage after weighting - to ensure that the demographic profile of the survey respondents matches that of the target universe - leads to an activity percentage of 79.2 instead of the unweighted 78.5.

Operationalizing "popularization" is difficult since there exists no entirely satisfactory definition. Instead, there is a continuous gradation, going from technical literature to popular science, with no clear-cut indication of where popularization begins (Hilgartner, 1990). In our questionnaire, we used the term "popularization" in a broad sense, i.e. as actions aimed at the non-specialized public, with the different possibilities explicitly included (in order of importance): conferences, lectures at universities (addressed to a "non-specialized" audience), radio interviews, newspaper interviews, television interviews, school lectures, articles in magazines (not specialized), websites, open doors, newspaper articles, science outreach books, magazine interviews (not specialized), lectures for associations (NGOs), science fairs, electronic interviews (Web), science café, radio programme or column and television programme or column.

Table 1. Summary of the main results of the survey by discipline

\begin{tabular}{lcccccc}
\hline Field & \# CONICET & \# respond & \# activities & \# active & \% active & \# actions per scientist \\
\hline Agrarian Sciences & 846 & 226 & 548 & 162 & 71.7 & 3.38 \\
Biological Sciences & 1630 & 353 & 782 & 213 & 60.3 & 3.67 \\
Exact Sciences & 1434 & 335 & 902 & 239 & 71.3 & 3.77 \\
Social Sciences & 988 & 231 & 1045 & 211 & 91.3 & 4.95 \\
Miscellaneous & 136 & 26 & 64 & 16 & 61.5 & 4.00 \\
Sum & 5034 & 1171 & 3341 & 841 & 71.8 & 3.97 \\
\hline
\end{tabular}




\section{Results}

\section{Who popularizes?}

The number of researchers who carried out at least one popularization activity in 2007 is remarkably high, almost three out of four researchers. This piece of data, which in principle might appear highly encouraging as regards to CONICET researchers' popularization activities, should be qualified, because a large proportion of researchers in the sample carried out few activities during the year (18.5\% just one, $13.7 \%$ two), suggesting it is an occasional activity rather than part of their usual tasks.

A logistic regression was applied to the data to study the influence on the popularization activity of the different scientists' characteristics: discipline, category, age, region and gender. We also included their perception of the difficulty of explaining their work to a general audience. Our results are summarized in Table 2.

Our analysis shows that social science researchers are clearly the most active, while biologists appear to be the least active. Other areas are not significantly different from our reference (physics). We also found that popularization increases for the higher categories. While over $90 \%$ of senior researchers (the highest position) carried out popularization activities, the percentage for assistants (the lowest position) is barely $64 \%$.

We found no correlation with age and performing popularization activities (for a fixed category), in contrast to French data, where, for a given position, activity significantly

Table 2. Logistic regression with a binary dependent variable (active in public outreach in 2007 or not) and categorical predictors

\begin{tabular}{|c|c|c|c|}
\hline Name & Coefficient & $\%$ odds ratio & $p$-value \\
\hline (Intercept) & 1.528 & 461 & $<0.001 * * *$ \\
\hline \multicolumn{4}{|l|}{ Field } \\
\hline Biological Sciences & -0.53 & 59 & $0.033^{*}$ \\
\hline Agrarian Sciences & -0.029 & 97 & 0.915 \\
\hline Mathematics & -0.43 & 65 & 0.355 \\
\hline Chemistry & -0.279 & 76 & 0.391 \\
\hline Social Sciences & 1.119 & 306 & $<0.001 * * *$ \\
\hline Earth Sciences & 0.218 & 124 & 0.506 \\
\hline \multicolumn{4}{|l|}{ Position } \\
\hline Senior & 1.025 & 279 & 0.128 \\
\hline Principal & -0.096 & 91 & 0.746 \\
\hline Adjunct & -0.618 & 54 & $0.004 * *$ \\
\hline Assistant & -0.73 & 48 & $0.01 * *$ \\
\hline \multicolumn{4}{|l|}{ Gender } \\
\hline Male & 0.328 & 139 & $0.023 *$ \\
\hline \multicolumn{4}{|l|}{ Difficulty } \\
\hline Very easy & 0.318 & 137 & 0.123 \\
\hline Hard & -0.572 & 56 & $0.001 * * *$ \\
\hline
\end{tabular}

The explanatory variables are: sex, position, discipline and opinion on the difficulty of popularizing. The reference levels are: "physics" for the discipline, "Independent" for the position and "easy" for the difficulty. The columns give the coefficients of the fit and their significance ( $p$-value). To interpret the results, one can use the " $\%$ odds ratio" which gives the ratio of the odds of a scientist being active and sharing this characteristic to the odds of a scientist being active in the reference group. For example, the odds that a social scientist is active are more than three times higher $(306 \%)$ than for a physicist.

Standard significance codes for the $p$-values have been used: $* * * 0<p<0.001 ; * * 0.001<p<0.01 ; * 0.01<$ $p<0.05$. 
decreases with age (Jensen, 2011). Our data show that women carry out fewer activities than men $(68 \%$ as opposed to $75 \%)$, and this difference is statistically significant. It is also interesting to note that women are slightly more active among CNRS (Centre National de la Recherche Scientifique) scientists (Jensen, 2011). Finally, scientists who think that popularizing their work is "difficult" are significantly less active than the others.

\section{What type of popularization do CONICET scientists carry out?}

Table 3 shows that the most common type of action is "conferences addressed to a wide audience" (not exclusively academic), which represent one quarter of the total.

Not all popularization activities appear to enjoy the same standing. Interviews on television, radio and in newspapers seem to be more prestigious and tend to be the preferred activity for senior researchers. On the other hand, activities such as talks at schools, open days or science fairs, appear to be aimed more at the participation of younger and junior researchers.

At the disciplinary level, social science researchers are the ones that differ most from the average. They give far more interviews in newspapers or speeches to NGOs (nongovernmental organizations) and take part in far fewer open days or science fairs. Biologists give fewer newspaper interviews and exact sciences researchers are involved in more science fairs and fewer talks with NGOs. There are no major differences in terms of gender.

Table 3. Percentages of the different types of popularization actions for each discipline and for the whole CONICET (last columns)

\begin{tabular}{|c|c|c|c|c|c|c|c|}
\hline & Agrarian Sci. & Biological Sci. & Exact Sci. & Social Sci. & Misc. & & um \\
\hline & $\%$ & $\%$ & $\%$ & $\%$ & $\%$ & $\%$ & $\#$ \\
\hline Conferences & 31.6 & 26.2 & 28.6 & 27.4 & 38.3 & 28.4 & 790 \\
\hline Radio interviews & 9.9 & 9.5 & 8.9 & 12.0 & 10.0 & 10.2 & 284 \\
\hline Newspaper interviews & 7.8 & 7.3 & 10.3 & 9.0 & 6.7 & 8.7 & 242 \\
\hline Television interviews & 5.3 & 6.2 & 6.7 & 6.9 & 3.3 & 6.3 & 176 \\
\hline School talks & 7.0 & 5.9 & 7.5 & 5.3 & 5.0 & 6.3 & 175 \\
\hline Magazine articles (not specialized) & 6.5 & 5.9 & 5.4 & 5.4 & 5.0 & 5.7 & 159 \\
\hline $\begin{array}{l}\text { Electronically published articles } \\
\text { (websites) }\end{array}$ & 5.7 & 5.0 & 3.3 & 5.6 & 5.0 & 4.9 & 136 \\
\hline Open doors & 6.5 & 5.9 & 4.6 & 2.9 & 5.0 & 4.7 & 131 \\
\hline Newspaper articles & 4.0 & 5.4 & 3.8 & 5.2 & 3.3 & 4.6 & 129 \\
\hline Science outreach books & 3.0 & 5.3 & 3.8 & 4.6 & 1.7 & 4.2 & 117 \\
\hline Magazine interviews (not specialized) & 3.4 & 3.9 & 4.3 & 3.8 & 8.3 & 4.0 & 111 \\
\hline Talks for civil associations (NGOs) & 2.5 & 4.0 & 2.4 & 5.2 & 1.7 & 3.7 & 102 \\
\hline Science fair & 3.4 & 3.1 & 4.7 & 1.2 & 1.7 & 2.9 & 82 \\
\hline $\begin{array}{l}\text { Electronically published interviews } \\
\text { (websites) }\end{array}$ & 2.1 & 3.1 & 3.2 & 3.0 & 3.3 & 2.9 & 82 \\
\hline Science café & 0.4 & 1.2 & 1.3 & 1.1 & 1.7 & 1.1 & 30 \\
\hline Radio host or panellist & 0.6 & 1.4 & 0.7 & 1.0 & 0.0 & 0.9 & 26 \\
\hline \multirow[t]{2}{*}{ TV host or panellist } & 0.2 & 0.8 & 0.6 & 0.1 & 0.0 & 0.4 & 11 \\
\hline & 100 & 100 & 100 & 100 & 100 & 100 & 2783 \\
\hline
\end{tabular}

The total of each column is equal to 100 , for each scientific department and for the whole CONICET. This allows us to compare directly the differences among disciplines for each type of action. For example, biologists perform relatively few "Newspaper interviews" (7.3 instead of the average 8.7) while "Exact" scientists are over-represented (10.3 instead of the average 8.7). 


\section{How easy or difficult do CONICET scientists find popularization?}

Our survey shows that the vast majority of researchers in all disciplines find it relatively easy to explain their work to a "non-expert" public. ${ }^{1}$ Those who report experiencing the least difficulties are the biological science researchers (over $80 \%$ regard it as "easy" or "very easy," and the percentage is even higher for medical science researchers, one of the Biological Sciences) which is remarkable since they belong to the disciplinary field that carries out the fewest popularization activities. The record for the reported degree of difficulty is held by mathematics, one of the disciplines included in the "Exact and Natural Sciences" category. It is interesting to compare these responses with the ones given by the CNRS researchers (Boy, 2007). Overall, $79 \%$ of them found popularization to be "easy or very easy," which is very similar to the CONICET average ( $76 \%)$.

\section{CONICET scientists' reasons to popularize}

Broadly speaking, amongst the reasons given by researchers for carrying out popularization activities, "altruistic" motivations, such as a "sense of duty," "raising awareness of the discipline" and even "transmitting the importance of science," predominate over motivations that are "strategic" or "political" (in a broad sense), such as "fighting the irrationality of the public," "justifying the use of public funding," "attracting students to my discipline" or "generating additional funds." This is comparable to the reasons given by European scientists (Boy, 2007; Royal Society, 2006).

One could argue that these responses are mostly rhetorical, i.e. linked to indisputable issues. They do not show a deep reflection on the role of scientific popularization and the motivations that compel researchers to carry it out.

A binomial regression including category, discipline and gender shows differences in the motivations for popularizing: social scientists favour "contributing to public debates on scientific topics" or "because it is a duty" ( $p$-value less than 0.0001). Physicists and men often answer "for pleasure" ( $p$-value 0.04 and 0.002 respectively); Adjuncts and Assistants feel less "duty" to popularize than the other categories ( $p$-value less than 0.01 ). Researchers who are

Table 4. Answers to the question: Why are you active in science outreach?

\begin{tabular}{|c|c|c|}
\hline Why are you involved in science popularization? & \# & $\%$ \\
\hline Because I feel it's my duty & 441 & 15.93 \\
\hline For the public to better understand science in general & 392 & 14.16 \\
\hline To inform about the importance of science in everyday life & 345 & 12.46 \\
\hline To contribute in public debates regarding scientific subjects & 209 & 7.55 \\
\hline For the public to get acquainted with my field of study & 188 & 6.79 \\
\hline To inform the public about the potential advantages of my work & 173 & 6.25 \\
\hline For the public to get acquainted with science production processes & 171 & 6.18 \\
\hline Because I like it & 167 & 6.03 \\
\hline To inform about the social and ethical influences of science & 167 & 6.03 \\
\hline To get new students interested in my field & 114 & 4.12 \\
\hline For my investigations to get greater visibility & 91 & 3.29 \\
\hline As a justification for the use of public funds & 71 & 2.56 \\
\hline To fight against the audience's lack of reason & 66 & 2.38 \\
\hline To fight against the "negative" image of science & 63 & 2.28 \\
\hline To get a better grasp of my own investigation & 57 & 2.06 \\
\hline To generate additional funds (subsidies) & 43 & 1.55 \\
\hline \multirow[t]{2}{*}{ I don't know } & 11 & 0.4 \\
\hline & 2769 & 100 \\
\hline
\end{tabular}


approaching retirement (60 to 69 years old) are specifically interested in popularization as a means of "fighting the irrationality of the public" ( $p$-value 0.002$)$.

\section{CONICET scientists' reasons not to popularize}

Leaving aside almost a quarter who state that they "do not know" why they do not popularize, the three dominant reasons are as follows: "Because it takes time away from my research." This appears to be a typical belief held by those who have never carried out this type of activity, as the actual time that certain activities would demand is, in relative terms, insignificant. The second-ranked response proves more interesting and refers to the "lack of institutional support or encouragement," since there is in fact no specific support or explicit evaluation of popularization activities. However, this variable does not appear to represent an insurmountable obstacle, given the high percentage of popularization actions observed in the sample as a whole. The third main reason (which only accounts for $10 \%$ of the sample of those who do not popularize), refers to the fact that the research topics "are too technical and difficult" to be popularized.

When those who have not carried out popularization activities are asked which factors would encourage them to do so, one out of five responses indicates they would do so if offered the chance, underlining the importance of two aspects: the role of journalists, who seek out certain researchers with greater frequency, and the role played by the institution in promoting these activities. Also, only one researcher out of two (in the whole sample) considers he/she is very or quite qualified, which suggests the need for some training in popularization activities.

\section{Scientists' opinions on "science and society" issues}

Dissemination activities are a part of a complex set of relationships among science and society. We have already stated that Argentine researchers - and generally those belonging to "peripheral" contexts - have had historically weak links with industry and the productive sector. Nonetheless and paradoxically, in their public discourses, they usually speak out in support of strengthening "science-society" links (Kreimer and Zabala, 2007; Polino et al., 2006). Therefore, it is interesting to investigate their opinions on a set of "social issues" potentially related to scientific research.

A logistic regression analysis (controlled for category, age and sex) shows that biologists think that GMO (genetically modified organism) production is an important issue ( $38 \%$ instead of $28 \%, p$-value $=0.00047)$. In general, researchers who are most involved in a specific problem are those who show most concern - in relative terms - about its consequences. Finally, gender differences are minor, except with the problems of pollution, women being much more concerned than men $(68 \%$ versus $59 \%, p$-value $=0.001)$.

The role of the state has also been a recurrent topic in scientific interventions in public arenas in the last three decades. Thus, we gathered scientists' opinions on the role (and intervention) of the state in implementing policies. We observed that the majority of scientists prefer a rather passive and limited role for the state. In fact, only slightly more than $20 \%$ agreed with orienting research to solve specific social problems and needs of Argentina, while $15 \%$ made traditional statements on the scientific community's autonomy ("it can't be conditioned"). These are the two extreme positions. The remaining vast majority (40\%) accept state intervention in scientific policy "only in certain areas" and just over $20 \%$ only "under certain conditions." 
Table 5 presents how scientists' characteristics influence the position on the question: "Do you think that research must be oriented to solve specific social problems and needs of Argentina?" Agricultural and Social scientists distinctly approve (29\% and 34\%, instead of $22 \%$ on average, $p$-values 0.001 and 0.00001 respectively) and scientists involved in popularization also share this opinion $(25 \%$ instead of $16 \%$ for the inactive, $p$-value $=0.015)$.

The prevalent belief among researchers is that scientific research should be guided by the scientific community. Any gearing to specific socio-economic objectives (which is part of most developed countries' policies) is perceived as solely subsidiary and solely for certain specific areas, or under certain particular conditions.

\section{Conclusions}

We have studied the popularization activities of researchers in Argentina, the incentives for and obstacles to popularizing, the opinions on issues such as the social role of scientific research, the orientation of research policies and the dangerous aspects of science. Our principal findings are the following:

Table 5. Logistic regression with a binary dependent variable (positive or negative answer) and categorical predictors to explain the scientists' opinions on social matters

\begin{tabular}{|c|c|c|c|c|c|c|}
\hline \multirow[b]{2}{*}{ Name } & \multicolumn{3}{|c|}{ Science for solving Argentina's problems? } & \multicolumn{3}{|c|}{ GMO production is an important issue } \\
\hline & Coefficient & $\%$ odds ratio & $p$-value & Coefficient & $\%$ odds ratio & $p$-value \\
\hline (Intercept) & -1.873 & & $4.32 \mathrm{E}-09 * * *$ & -1.081 & & $3.97 \mathrm{E}-05^{* * *} *$ \\
\hline \multicolumn{7}{|l|}{ Field } \\
\hline Biological Sci. & 0.287 & 133 & 0.354 & 0.651 & 192 & $0.008 * *$ \\
\hline Agrarian Sci. & 0.940 & 256 & $0.002 * *$ & 0.339 & 140 & 0.197 \\
\hline Math. & 0.075 & 108 & 0.903 & -1.349 & 26 & $0.079 \dagger$ \\
\hline Misc. & 1.021 & 278 & $0.095 \dagger$ & 0.289 & 134 & 0.623 \\
\hline Chemistry & -0.090 & 91 & 0.835 & 0.331 & 139 & 0.304 \\
\hline Social Sci. & 1.158 & 318 & $<0.001 * * *$ & 0.293 & 134 & 0.264 \\
\hline Earth Sci. & 0.674 & 196 & $0.058 \dagger$ & -0.264 & 77 & 0.420 \\
\hline \multicolumn{7}{|l|}{ Position } \\
\hline Senior & -0.603 & 55 & 0.235 & -0.485 & 62 & 0.253 \\
\hline Principal & 0.061 & 106 & 0.825 & -0.041 & 96 & 0.870 \\
\hline Adjunct & 0.070 & 107 & 0.719 & 0.088 & 109 & 0.611 \\
\hline Assistant & -0.006 & 99 & 0.976 & -0.104 & 90 & 0.567 \\
\hline \multicolumn{7}{|l|}{ Gender } \\
\hline Male & 0.159 & 117 & 0.279 & -0.064 & 94 & 0.626 \\
\hline Pop. activity & 0.424 & 153 & $0.018 *$ & -0.014 & 101 & 0.923 \\
\hline
\end{tabular}

The explanatory variables are: sex, discipline, position and popularization activity. The reference levels are: "physics" for the discipline and "Independent" for the category. The columns give the coefficients of the fit and their significance ( $p$-value). To interpret the results, one can use the "\% odds ratio" which gives the ratio of the odds of a scientist answering "yes" and sharing this characteristic to the odds of a scientist answering "yes" in the reference group. For example, the odds that a social scientist thinks that science should aim at solving Argentina's problems are more than three times higher $(318 \%)$ than for a physicist.

$* * *<<0.001 ; * * 0.001<p<0.01 ; * 0.01<p<0.05 ; \dagger 0.05<p<0.1$. 
- The number of researchers who carried out at least one popularization activity is remarkably high: almost three out of four. This is very positive and in line with Kyvik's (this issue, 2011) international survey which ranks Argentina as the most active country in popularization. However, our data also show that almost a quarter of "active" scientists carried out only one activity over the entire year, which represents nearly $20 \%$ of the total population. It can be argued that for scientists who undertake a single activity per year, popularization is just an occasional practice. Therefore, if we add these "occasional" popularizers to the $28 \%$ of the whole sample who carried out no activity, the overall picture changes: almost half of CONICET scientists should not be considered as fully active in popularization. Social and human science researchers are clearly the most active and those from the biological sciences appear to be the least active. Although this difference is found in most countries, the reasons for the limited popularization activity by CONICET biologists are worth investigating in the future. As this area includes the biomedical sciences, it is noteworthy that the scientists working in this field have not engaged in significant public participation with regards to several major health issues that have emerged during recent years (i.e. Chagas' disease, dengue and other tropical or "local" endemic issues) (Kreimer and Zabala, 2007).

- We found that senior and junior scientists do not carry out the same type of popularization activities. Prestigious activities such as interviews on television or in newspapers are more frequent among senior scientists, while junior researchers are more active in less prestigious activities like open doors or school talks. There could be two reasons for this: the most obvious is the unwillingness of senior researchers to take part in activities aimed at the less qualified "lay" public, such as in schools, when compared to the diffusion achieved by activities in the mass media. But, an important role is also played by scientific journalists (even more so by journalists in general), who usually require the opinion of "experts" on certain issues emerging in the public arena (climate change, GMOs, epidemics, energy, etc.), where, almost by definition, these experts are the most prestigious and highest-ranking researchers.

- Most of these features are similar to what is observed in European countries (Jensen, 2011; Royal Society, 2006). The increase in activity for the highest positions can be explained by several factors: the more advanced researchers carry greater authority and often speak "on behalf of" the group or institute where they work. This "division of scientific work" also corresponds to what sociologists have observed in the everyday practices of scientists (Shinn, 1988). Finally, it is the most experienced researchers who are usually sought after by the media as "experts."

To conclude, we return to the question of differences in popularization practices in "central" and "peripheral countries." In this study, we have not observed major differences between the popularization practices of Argentine and European (French and British) scientists. This is somewhat surprising for at least two reasons. Firstly, the research practices in both types of countries are different, challenging the traditional ideal of universalism of scientific activities (Vessuri, 1997). Indeed, the agenda setting, the availability of material and symbolic resources, and the proportion of researchers over the active population are significantly different in both contexts. Furthermore, research activities in peripheral countries are traditionally autonomous, and separated from industry and other social uses (Kreimer and Zabala, 2007). Secondly, there exists a crucial contrast in the degree of the intensity of sciencesociety relationships in developing countries (traditionally weak) compared to the developed ones (traditionally strong) (Kreimer and Thomas, 2006). However, CONICET researchers 
seem to have popularization practices similar to their "central" colleagues'. This points to the hypothesis of a "universal scientific community," tightly linked and sharing common values that shows an alignment of local scientists with "global" values. Several hypotheses can be proposed to explain this particularity of popularization:

- Popularization activities are part of a "universal ideological package," that is to say, a set of values shared by scientists all around the world. This universality is reinforced by the growing participation of "peripheral" scientists in large research networks including "central" scientists.

- Popularization does not need expensive resources or equipment that peripheral countries lack.

- The growing perception of "global challenges," such as biodiversity, global warming and climate change, has pushed media and scientists all around the world to be more active in the public arena. This trend is reinforced by the development of scientific journalism in both central and peripheral countries.

Further investigation is needed to ascertain the relevance and weight of these hypotheses.

\section{Acknowledgement}

We are happy to thank Cynthia Jeppesen and CONICET staff for providing the e-mail addresses of the CONICET scientists.

\section{Note}

1 We include here all respondents, whether they effectively popularized or not.

\section{References}

Boy, D. (2007) “Enquête sur la responsabilité sociale du scientifique,” URL (accessed 14 December 2009): http:// www.cnrs.fr/colloques/sciences-societe/docs/enqueteBoy.pdf

Gaillard, J., Krishna, V.V. and Waast, R. (1996) Scientific Communities in the Developing World. New Delhi: SAGE Publications.

Hilgartner, S. (1990) “The Dominant View of Popularization: Conceptual Problems, Political Uses,” Social Studies of Science 20(3): 519-39.

Jensen, P. (2011) "A Statistical Picture of Popularization Activities and their Evolutions in France," Public Understanding of Science this issue.

Kreimer, P. (1998) "Understanding Scientific Research on the Periphery: Towards a New Sociological Approach?," EASST Review 17(4).

Kreimer, P. and Thomas, H. (2006) "Production des connaissances dans la science périphérique: l'hypothèse CANA en Argentine," in J.B. Meyer and M. Carton (eds) La société des savoirs. Trompe-l'œil ou perspectives?, pp. 143-67. Paris: L'Harmattan.

Kreimer, P. and Zabala, J.P. (2007) "Chagas Disease in Argentina: Reciprocal Construction of Social and Scientific Problems," Science, Technology and Society 12(1): 49-72.

Lemaine, G. (1980) "Science normale et science hypernormale. Les stratégies de différenciation et les stratégies conservatrices dans la science," Revue française de sociologie XXI(4): 499-527.

Polanyi, M. (1964) Science, Faith, and Society. Chicago: University of Chicago Press.

Polino, C. et al. (2006) “Análisis de la oferta informativa sobre ciencia y tecnología en los principales diarios argentines.” Buenos Aires: SECYT.

Royal Society (2006) "Factors Affecting Science Communication: A Survey of Scientists and Engineers," URL (accessed 28 May 2010): http://royalsociety.org/uploadedFiles/Royal_Society_Content/Influencing_Policy/ Themes_and_Projects/Themes/Governance/Final_Report_-_on_website_-_and_amended_by_SK.pdf 
Salomon, J.-J., Sagasti, F. and Sachs, J. (1994) The Uncertain Quest: Science, Technology and Development. Tokyo, New York, Paris: United Nations University Press.

Schwartzman, S. (1991) A Space for Science: The Development of the Scientific Community in Brazil. Philadelphia: Penn State Press.

Shinn, T. (1988) "Hiérarchies des chercheurs et formes des recherché," Actes de la recherche en sciences sociales 74: $2-22$.

Vessuri, H. (1983) La Ciencia periférica. Caracas: Monte Avila.

Vessuri, H. (1997) "Science for the South in the South: Exploring the Role of Local Leadership as a Catalyst of Scientific Development," in T. Shinn, J. Spaapen and V.V. Krishna (eds) Science and Technology in a Developing World: The Sociology of the Sciences Yearbook 1997, pp. 299-321. Dordrecht: Kluwer Academic Publishers.

Weigold, M.F. (2001) “Communicating Science: A Review of the Literature,” Science Communication 23(2): 164-93.

\section{Authors}

Pablo Kreimer has studied the relationships between science and society in a wide sense: on the one hand, he has approached the social uses of scientific knowledge, the orientation of research and the building of scientific agendas to approach social needs, the history of scientific fields related to social issues, and the practices of popularization carried out by diverse scientists. On the other hand, he has studied the international relationships between scientists from "peripheral" countries with their colleagues from "central" ones, analyzing the implication in large international networks, as well as their "informal" collaboration links.

Luciano Levin is a chemist and biotechnologist finishing his $\mathrm{PhD}$ in social studies of sciences. He studies the relationships between drug addiction treatments and the production of knowledge in Argentina. He works as a scientific journalist and as scientific advisor in outreach practices and the organization of outreach activities in several governmental offices. He also manages a project searching for ways to use science fictions films in science education practices and outreach activities. Correspondence: IEC-UNQ, Roque Sáenz Peña 352, Bernal (B1876BXD) - Buenos Aires, Argentina; e-mail: lulevin@fibertel.com.ar

Pablo Jensen is a physicist working at the Ecole Normale Supérieure de Lyon and the RhôneAlpes Complex Systems Institute (IXXI, www.ixxi.fr). After 15 years devoted to the modelling of nanostructures, he is currently using quantitative tools to study social systems. He has been deeply involved in public outreach: creation of scientific and junior cafés (1997), a book giving a "realistic" vision of condensed matter physics (Des atomes dans mon café crème, Seuil, 2004). He has also been in charge of popularization at CNRS (2001-5). This position leads him to study scientists' public outreach practices. 